\title{
Vitamin D and its effects on cardiovascular diseases: a comprehensive review
}

\author{
Nonanzit Pérez-Hernández ${ }^{1}$, Gad Aptilon-Duque ${ }^{1,2}$, María Cristina Nostroza-Hernández ${ }^{1}$ \\ Gilberto Vargas-Alarcón ${ }^{1}$, José Manuel Rodríguez-Pérez ${ }^{1}$, and Ruben Blachman-Braun ${ }^{1,2}$
}

${ }^{1}$ Department of Molecular Biology, National Institute of Cardiology "Ignacio Chavez", Mexico City; ${ }^{2}$ Faculty of Health Sciences, Anahuac University, Huixquilucan, Mexico
Vitamin D is a molecule that is actively involved in multiple metabolic pathways. It is mostly known for its implications related to calcium metabolism. It has also been determined that it actively participates in the cardiovascular system, influencing blood pressure, coronary artery disease and other vascular diseases, such as heart failure and atrial fibrillation. Furthermore, it has been established that this vitamin is extensively involved in the regulation of both the renin angiotensin aldosterone system and the immune system. In this review, we present the different vitamin D metabolic pathways associated with the cardiovascular pathophysiology, and we include studies in animal and human models, as well as some of the controversies found in the literature. This review also incorporates an overview of the implications in the molecular biology and public health fields.

Keywords: Vitamin D; Cardiovascular system; Metabolic networks and pathways

\section{Correspondence to \\ Ruben Blachman-Braun, M.D.}

Department of Molecular Biology, National Institute of Cardiology "Ignacio Chavez", Juan Badiano No. 1, Col. Sección XVI, Tlalpan 14080, Mexico City, Mexico

Tel: $+52-55-55732911$

Fax: +52-55-551365811

E-mail: rubenblach@gmail.com

Nonanzit Pérez-Hernández, Ph.D.

Department of Molecular Biology, National Institute of Cardiology "Ignacio Chavez", Juan Badiano No. 1, Col. Sección XVI, Tlalpan 1408o, Mexico City, Mexico

Tel: $+52-55-55732911$

Fax: $+52-55-551365811$

E-mail: unicanona@yahoo.com.mx homeostasis, when he correlated rickets found in children with little exposure to sunlight from industrialized cities $[1,2]$.

In the last decades, an increasing interest has arisen regarding the role that vitamin $\mathrm{D}$ plays in the metabolism of the different human organs and systems. There is a complex biologic interaction between this molecule 
and the organism; namely, its receptors are involved in several signalling pathways, and are not only related to calcium metabolism $[3,4]$.

It is estimated that $30 \%$ to $50 \%$ of worldwide population suffers a form of vitamin $\mathrm{D}$ deficiency. This has been proven to be more frequent in populations living more distant to the equatorial line, resulting in important repercussions to their well-being and health [4]. The connection between the lack of vitamin $\mathrm{D}$ and a number of diseases is well established. Some of these diseases are cancer [5], psoriasis [6], asthma [7], rheumatoid arthritis [8], multiple sclerosis [9], inflammatory bowel disease [10], insulin resistance [11], type 2 diabetes mellitus (T2DM), metabolic syndrome, obesity, hypertension, and cardiovascular disease [4].

Despite the fact that several studies have been published on this topic, knowledge about the relation between vitamin D and cardiovascular disease is still lacking, for the detriment of healthcare professionals. This review presents the most relevant and most recent published information on the subject, referring to a wide variety of molecular, animal, and human studies. In this article, we have also taken into account the different aspects, in which vitamin $\mathrm{D}$ is presumably involved with the various aspects of cardiovascular diseases. Therefore, the aim of this article is to elucidate to physicians the different associations and mechanisms regarding vitamin $\mathrm{D}$ and cardiovascular disease, with an objective perspective.

\section{MATERIAL AND METHODS}

In this review, we conducted an exhaustive search in Scopus, EBSCO, and PubMed and looked for the most recent evidence in articles about vitamin $\mathrm{D}$ and cardiovascular system.

\section{Metabolism}

Vitamin $\mathrm{D}_{3}$ (cholecalciferol) is a steroid hormone found in nature, and can be acquired from various sources [12], including cow milk, eggs, fish (salmon and tuna), and eel. It is absorbed by the gastrointestinal tract. In addition, 7-dehydrocholesterol, a serum circulating cholesterol precursor, is converted to cholecalciferol in the skin when exposed to ultraviolet B (UVB, 280 to $315 \mathrm{~nm}$ ) and carried to the liver by the vitamin D-binding protein (Gc-globulin). Then, it is hydroxylated on position C-25 into 25-hydroxyvitamin D (calcifediol, 25(OH)D, or $\left.{ }_{25}(\mathrm{OH}) \mathrm{D}_{3}\right)$ by the 25 -hydroxylase, an enzyme located in the cytochrome $\mathrm{P}_{450}$ (CYP2R1, CYP2D11, and CYP2D25).

The $25(\mathrm{OH}) \mathrm{D}$ is a major metabolite circulating in blood. It is transported by vitamin D-binding protein to the kidneys, where it is transformed into 1,25-dihydroxyvitamin $\mathrm{D}$ (calcitriol, 1,25( $\mathrm{OH}) \mathrm{D}$ or $1,25(\mathrm{OH})_{2} \mathrm{D}_{3}$ ) by the $1 \alpha$-hydroxylase enzyme of the proximal convoluted tubule. 1,25( $\mathrm{OH}) \mathrm{D}$ destined for excretion is finally metabolized in the kidneys, where it is transformed initially into $24,25(\mathrm{OH})_{2} \mathrm{D}_{3}$, next into $1,24,25(\mathrm{OH})_{2} \mathrm{D}_{3}$ (1,24,25-dihydorxyvitamin D) and finally into calcitroic acid, which is then excreted through urine (Fig. 1) [13-16].

Since this enzyme is present in various tissues, such as placenta, monocytes, and macrophages, the aforementioned process is not exclusive of the kidneys. $1,25(\mathrm{OH})_{2} \mathrm{D}_{3}$ is responsible for most of vitamin $\mathrm{D}$ metabolic actions, including those related to calcium $[13,14]$.

Apart from the classical metabolic action of $1,25(\mathrm{OH})_{2} \mathrm{D}_{3}$ over calcium, phosphate and the parathyroid hormone (PTH), other complex metabolic actions are mediated by vitamin D receptors (VDRs). VDRs are intracellular

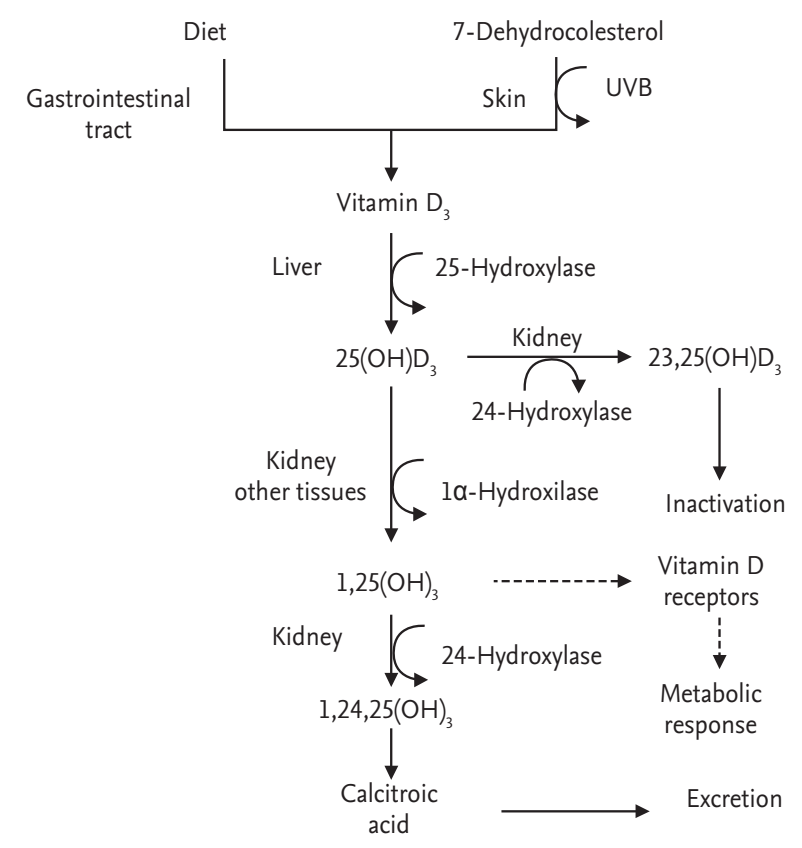

Figure 1. Schematic representation of vitamin $\mathrm{D}$ metabolism. UVB, ultraviolet B; $25(\mathrm{OH}) \mathrm{D}_{3}$, 25-hydroxyvitamin D. 
receptors which bind $1,25(\mathrm{OH})_{2} \mathrm{D}_{3}$, and are found in over 36 tissues, including vascular smooth muscle, endothelium, and myocardium. Interestingly, VDRs play a crucial role in the homeostasis, hence actively regulating the cardiovascular system [13-17].

\section{Serum levels variation and its risk factors}

Variations in serum levels of the vitamin D metabolites have many clinical implications, and different scales to classify these levels have been suggested [18-20]. The Institute of Medicine concluded that $25(\mathrm{OH}) \mathrm{D}$ serum levels of $16 \mathrm{ng} / \mathrm{mL}$ covers the requirements of approximately $50 \%$ of the population, $25(\mathrm{OH}) \mathrm{D}$ serum levels of $20 \mathrm{ng} /$ $\mathrm{mL}$ covers the requirements of $\geq 97.5 \%$ of the population, while $25(\mathrm{OH}) \mathrm{D}$ levels of $50 \mathrm{ng} / \mathrm{mL}$ or greater should raise concerns about potential adverse effects [21]. On the other hand, the U.S. Endocrine Society guidelines defines vitamin $\mathrm{D}$ deficiency as $25(\mathrm{OH}) \mathrm{D}$ less than $20 \mathrm{ng} / \mathrm{mL}$ (50 nmol/L), vitamin D insufficiency as a $25(\mathrm{OH}) \mathrm{D}$ level between 21 and $29 \mathrm{ng} / \mathrm{mL}$, and the safety margin to minimize the risk of hypercalcemia as a $25(\mathrm{OH}) \mathrm{D}$ level equal to $100 \mathrm{ng} / \mathrm{mL}$ (250 $\mathrm{nmol} / \mathrm{L})$ [22].

Several risk factors may condition and predispose to vitamin $\mathrm{D}$ deficiency, for instance, low exposure to sunlight, skin hyperpigmentation, low dietary intake, smoking, pollution, aging, sedentarism, intestinal malabsorption, kidney disease, liver disease, and deficiency secondary to medication and genetic factors $[20,23,24]$. Obesity is associated with low serum $25(\mathrm{OH}) \mathrm{D}$ levels, which could be the result of several mechanisms. One hypothesis suggests that a high content of body fat acts as a reservoir for lipid soluble vitamin $\mathrm{D}$. This increases its sequestration, and evokes a low bioavailability. Other hypotheses suggest that higher leptin and interleukin 6 (IL-6) circulating levels, mostly secreted by adipose tissue, may have inhibitory effects on $25(\mathrm{OH}) \mathrm{D}$ synthesis via their receptors [25].

\section{Coronary artery disease and other vascular diseases}

Coronary artery disease (CAD) remains the main cause of death in developing countries. It is a disease of multifactorial etiology in which metabolic, genetic, hemodynamic, and inflammatory factors are involved $[26,27]$. Just as in other cardiovascular diseases, it has been established that vitamin $\mathrm{D}$ plays an active role in $\mathrm{CAD}$ through different mechanisms, as elucidated next [28].
In animal models, it has been established that vitamin D plays an active role in arterial hardening and endothelial function, mediated by both VDRs and $1 \alpha$-hydroxylase found in these tissues. Endothelial dysfunction is caused by a reduction in nitric oxide bioavailability in VDR deficient mice [29]. In addition, vitamin D makes a counter regulatory process in the renin-angiotensin-aldosterone system (RAAS) by diminishing its proliferating effects on the vascular smooth muscle cells, and reducing $\mathrm{CAD}$ [30].

Research has shown that vitamin D protects vessel walls against damage caused by inflammation by increasing the expression of anti-inflammatory cytokines, such as IL-10, and by decreasing expression of pro-inflammatory molecules, e.g., tumor necrosis factor $\alpha$ (TNF- $\alpha$ ) and IL-6 [31]. Vitamin D is also involved in the down-regulation of plaque-destabilizing enzymes, like matrix metalloproteinase 9 (MMP-9) [32], as well as in the C-reactive protein elevation. Yet, the involvement of the latter is not supported by recent studies [33].

In vitro models, using human umbilical cord endothelial cells, suggest that vitamin D may be useful in treating acute coronary syndromes by reducing VCAM-1 (vascular cellular adhesion molecule), MMP-1, and CD62P (P-selectin) expression, and indirectly regulating platelet aggregation [34]. Vitamin D is also now considered a prognostic factor for acute myocardial infarction and CAD [32,35-37]. In addition, Jablonski et al. [38] found endothelial dysfunction in adults with low $25(\mathrm{OH}) \mathrm{D}_{3}$, as opposed to patients with normal levels, through the measurement of nuclear factor $-\kappa \mathrm{B}(0.59 \pm 0.07$ vs. $0.44 \pm$ $0.05, p<0.05)$ and other pro-inflammatory cytokines in endothelial cells.

Accordingly, vitamin D contributes to vascular structure, function and remodeling, as well as to the pathophysiology of endothelial dysfunction and atherosclerosis. Low vitamin D serum levels have been identified as a potential risk factor for death, (odds ratio [OR], 1.16; 95\% confidence interval [CI], 1.012 to $1.334 ; p=0.03$ ) [3941]. To demonstrate this, Seker et al. [42] compared 69 adults with vitamin D deficiency to a group of 62 healthy non-vitamin D-deficient people. They calculated pulse wave velocity in both groups, finding that it was statistically higher $(p<0.02)$ in the vitamin $\mathrm{D}$ deficient group, indicating vascular stiffness and endothelial dysfunction. These findings match those of Al Mheid et al. [43], 
which connect vitamin D deficiency to vascular disease.

Syal et al. [44] reported that severe CAD (double or triple vessel $\mathrm{CAD}$ ) was more frequent in patients with $25(\mathrm{OH}) \mathrm{D}$ levels $<20 \mathrm{ng} / \mathrm{mL}$ as compared to those with levels $>20 \mathrm{ng} / \mathrm{mL}$ ( $53 \%$ vs. $38 \%, p=0.03$ ). Diffuse CAD on coronary angiography was also more frequently present in those with lower $25(\mathrm{OH}) \mathrm{D}$ levels ( $56 \%$ vs. $38 \%, p=0.03$ ). In addition, the mean number of coronary vessels involved was also higher in those with lower $25(\mathrm{OH}) \mathrm{D}$ levels (1.78 \pm 0.76 vs $1.24 \pm 0.43, p=0.05)$ [44]. Chen et al. [45] proposed that low vitamin $\mathrm{D}$ levels are associated with the severity of coronary artery stenosis and Joergensen et al. [46] postulated that diabetic patients with vitamin $\mathrm{D}$ deficiency have a higher risk to develop $\mathrm{CAD}(\mathrm{OR}, 2.9$; 95\% CI, 1.02 to 7.66). In addition, it has been reported that HIV positive African-Americans with a vitamin D deficiency have a higher risk for presenting coronary artery stenosis (OR, 2.28; 95\% CI, 1.23 to 4.21) [47].

Vitamin D also plays a role in vascular calcification, a multifactorial process with deep clinical implications $[48,49]$. Vitamin D regulates PTH, which in turns mediates calcium metabolism; vascular calcification is a common complication when this pathway is modified. In addition, vitamin $\mathrm{D}$ interacts with fibroblast growth factor 23, Klotho enzyme, phosphate, and a large range of immunological and metabolic pathways. Vascular calcification is related to all these factors, and is therefore linked to vitamin $\mathrm{D}[13,50,51]$. Randomized studies in low density lipoprotein (LDL) receptor knockout $\left(\mathrm{LDLR}^{-/-}\right)$ mice fed with a low vitamin $\mathrm{D}$ diet, have demonstrated enhanced vascular calcification. This is probably related to the observation that a low vitamin $\mathrm{D}$ diet modifies expression of vascular osteoblast differentiation factors and verifiable osteoblast-like cells [52]. However, highdose calcitriol treatment induces an osteoblastic phenotype in vascular smooth muscle cells, both in subtotally nephrectomized rats and in vitro. This effect is associated with an up-regulation not only of proteins regulating mineralization and calcium transport, but also of osterix (osteogenic transcription factor) [53].

A small study in apolipoprotein E-deficient mice has postulated a novel cardioprotective role for VDRs in circulating endothelial cells. In this study, authors suggest that VDR deficiency not only promoted the development of atherosclerosis, but also decreased the stability of atherosclerotic plaques. This happens through mech- anisms that include cell proliferation and differentiation, apoptosis, oxidative stress, membrane transport, matrix homeostasis, and cell adhesion. Additionally, they suggest that VDRs up-regulates eNOS (endothelial nitric oxide synthase) protein expression, an important enzyme that contributes to the pathogenic process of atherosclerosis [54].

Interestingly, just like vitamin D deficiencies, hypervitaminosis or a state of toxicity will lead to vascular calcification. This observation was made in dialysis patients where a U-shape curve has been noticed, where low serum vitamin D levels, as well as high levels, are associated with vascular calcification $[13,50,51]$. However, other authors have postulated that there is insufficient evidence to support a consistent association between low vitamin D levels and coronary artery calcium (CAC) [55], or that there is definitely no association between low $25(\mathrm{OH}) \mathrm{D}$ and CAC, or severely obstructive coronary artery stenosis [56]. Nevertheless, single nucleotide polymorphisms (SNPs) in the CYP24A1 gene, associated with vitamin D metabolism, have been independently linked with coronary artery calcification [57]. For this reason, future studies should analyze the results in the light of the genetic population variability, taking into account the SNPs that affect the VDRs or enzymes that are related with vitamin D metabolism. These studies should also evaluate serum $25(\mathrm{OH}) \mathrm{D}$ and its relationship to subclinical coronary atherosclerosis.

Indeed, vitamin D deficiency has also been identified as a potential risk factor for peripheral artery disease (OR, 1.35; 95\% CI, 1.15 to 1.59) [58], if $25(\mathrm{OH}) \mathrm{D}_{3}$ levels decrease below $10 \mathrm{ng} / \mathrm{mL}$ [59]. In addition, Chaudhuri et al. [6o] estimated that $25(\mathrm{OH}) \mathrm{D}_{3}$ deficiency may also be a risk factor for ischemic stroke (OR, 1.6; 95\% CI, 1.2 to $2.8)$, concurring with other authors who report $25(\mathrm{OH}) \mathrm{D}_{3}$ levels as prognostic and severity predictors in patients with ischemic stroke [61].

\section{Hypertension}

Systemic arterial hypertension is a severe public health issue [62]. Hypertension is considered an isolated cardiovascular risk factor; however, it is associated with $\mathrm{CAD}$, stroke, and renal failure $[63,64]$, and has a multifactorial etiology. Even more, it has been demonstrated that RAAS plays a major role in hypertension pathophysiology, affecting sodium reabsorption in the kidney, as 
well as vasculature reactivity [65].

A recent meta-analysis has postulated that vitamin $\mathrm{D}$ is involved in this disease, showing that patients with low $25(\mathrm{OH}) \mathrm{D}_{3}$ serum levels may have more risk to develop hypertension compared to those with normal parameters (OR, 1.37; 95\% CI, 1.19 to 1.59) [66]. It is believed that this molecule takes part in the process via different mechanisms, but its effect over RAAS, as mentioned above, is one of the most important [67]. Animal models show that calcitriol binds to the promoter region in the $R E N-1 C$ gene and thus suppresses renin expression, lowering the risk to develop hypertension. Furthermore, renal arteries in vitamin $\mathrm{D}$ deficient individuals have lower expression of angiotensin-1 receptors, when they are exposed to the molecule [68]. Studies demonstrate that VDR and $1 \alpha$-hydroxylase knockout mice develop hypertension due to a higher expression of renin [69,70]. They also report that vitamin $\mathrm{D}$ deficient diets predispose to an accelerated activation of RAAS with subsequent hypertension and atherosclerosis [71]. Hence, vitamin D could be a cardiovascular protection factor.

Another mechanism through which low levels of vitamin D may exert influence to hypertension generation, is by direct interaction with the endothelium and vasculature [72]. Chronic treatment with calcitriol has shown that hypertensive rats have decreased endothelium dependent vascular contraction, reduced quantities of reactive oxygen species, and diminished expression of cyclooxigenase-1 [73], which suggests that vitamin D directly confers a protective function against endothelial dysfunction [74].

A third mechanism suggested in the implication of vitamin D and hypertension is regarding PTH and calcium metabolism. Hypovitaminosis D brings about an increment in PTH secretion, which will, at first, relax the vasculature and will eventually constrict it, thereby causing hypertension. Pathophysiologically, this will happen due to an increase of intracellular calcium levels, resulting in endothelial and vascular growth dysfunction [75]. Population studies also support these theories [76-78]. Rostand [79] postulated that the farther a population is settled from the equatorial line, the higher its blood pressure will be, estimating that for every 10 degrees of distance, pressure will rise $2.5 \mathrm{mmHg}$. This suggests that the relationship is established based on exposure to sunlight and consequent vitamin D avail- ability. Forman et al. [80] showed that angiotensin-II levels are statistically different $(p=0.03)$ in individuals with regular calcifediol levels compared to those with insufficient to deficient levels.

Additionally, in their double-blind study, Nasri et al. [81] showed that supplementary therapy with cholecalciferol based on 50,000 units weekly for 12 weeks, reduces blood pressure significantly $(p<0.01)$ in diabetic patients. This result is line with the data presented by Larsen et al. [82], who reported that a daily supplementation of 3,000 units of cholecalciferol reduces central systolic pressure $(p=0.007)$. Although vitamin D supplementation has not been proven as a beneficial treatment for hypertension in all ethnic and age groups [81], Forman et al. [83] suggested that it is indeed beneficial, specifically in the case of the African-American population. Similarly, Judd et al. [84] observed in a case-control study that patients under calcitriol supplement treatment ( $0.5 \mu \mathrm{g}$ twice daily) have a statistically significant lower blood pressure $(p<0.001)$. Nonetheless, it has been shown that there is no benefit in vitamin D supplementation in geriatric population with isolated systolic hypertension [85].

Even though one meta-analysis has shown that, in patients with the diagnosis of hypertension, supplementary vitamin $\mathrm{D}$ can reduce the diastolic blood pressure $-3.1 \mathrm{mmHg}(95 \% \mathrm{CI},-5.5$ to -0.6$)$ and the systolic blood pressure $-6.2 \mathrm{mmHg}$ ( $95 \% \mathrm{CI},-12.32$ to -0.04 ), supplementary vitamin D has no effect in patients without hypertension [86]. Other authors support the hypothesis that vitamin D supplementation is ineffective to lower blood pressure in the general population, and thus advice against its use as an antihypertensive agent $[87,88]$.

Regarding pulmonary hypertension, Demir et al. [89] estimated that there is a statistically significant difference $(p<0.001)$ in the systolic pulmonary artery pressure in patients with low levels of vitamin D (36.31 \pm 8.99 $\mathrm{mmHg}$ ) and those with adequate serum levels (32.42 \pm $8.06 \mathrm{mmHg}$ ). This promising result notwithstanding, currently there is not enough evidence to correlate pulmonary hypertension and vitamin D levels abnormalities.

\section{Heart failure and vitamin D}

Worldwide, heart failure (HF) represents a major health problem with an incidence of $1 \%$ to $2 \%$. It is considered 
a complex disease with multiple causes. Actually, vitamin D and its metabolic pathway have been described as related agents for HF, both in the development and progression of the disease $[90,91]$.

In rats, vitamin $\mathrm{D}$ is a protective factor in the development of ventricular hypertrophy and cardiac dysfunction [92]. Alternatively, studies in swine suggest that vitamin D deficiency, diminished expression of both VDRs and the suppressor of cytokine signaling $3\left(\mathrm{SOCS}_{3}\right)$ gene are associated to myocardial hypertrophy [93].

In a clinical trial, Shedeed [94] studied 80 children with congestive HF and divided them into two groups; the first one received vitamin $\mathrm{D}$ supplementation for 12 weeks, and the second one received a placebo. The evaluation at the end of the period reports a significant improvement in the former group regarding the ejection fraction of the left ventricle, as well as an increase in IL-10 and a decline in PTH, IL-6, and TNF- $\alpha$ [94]. This might be explained by the inhibitory processes that vitamin D plays in RAAS [95]. In addition, after studying a large population, Ford et al. [96] suggested that vitamin D supplementation might protect against cardiac failure in older people. Furthermore, it has been postulated that serum levels of $25(\mathrm{OH}) \mathrm{D}$ may be a marker and a modulator of the functional capacity in $\mathrm{HF}$ of the elderly [97].

Other studies, however, are inconclusive when demonstrating that vitamin $\mathrm{D}$ or vitamin $\mathrm{D}$ carrier protein deficiency has a role in $\mathrm{HF}[98,99]$. As a result, it is important to bear in mind that further studies need to be performed before drawing conclusions on the role of vitamin $\mathrm{D}$ in HF.

\section{Atrial fibrillation}

Atrial fibrillation (AF) is estimated to have a prevalence of $2 \%$ in the world population and has multifaceted implications in health and quality of life [10o]. Valvular abnormalities, hypertension, and diabetes have been associated to AF. Actually, genetics and molecular pathways are deeply involved in the development of the disease [101].

It was not until 1990, when Kessel [102] described the possible correlation between vitamin D and AF. Even though the exact connection is still unknown, we can hypothesize a correlation between them from two facts: calcitriol contributes to smooth muscle proliferation and affects the RAAS, and angiotensin II levels are above normal in $\mathrm{AF}$ [103]. Some literature suggests that $25(\mathrm{OH})$ $\mathrm{D}_{3}$ levels are deficient in patients diagnosed with $\mathrm{AF}$ $[104,105]$. By way of contrast, it has been reported that individuals with $25(\mathrm{OH}) \mathrm{D}$ levels higher than $100 \mathrm{ng} / \mathrm{mL}$ have a greater risk to suffer from $\mathrm{AF}$ [106]. And yet, other studies have shown that there is no correlation between vitamin $\mathrm{D}$ and $\mathrm{AF}[107,108]$. The current evidence is consequently insufficient to sustain the correlation between $\mathrm{AF}$ and vitamin $\mathrm{D}$.

\section{Insulin resistance}

Vitamin D status is inversely associated with total body fat. A higher storage in adipose tissue is a plausible explanation for increased rates of deficiency in obese patients [109]. Indeed, an important correlation between vitamin $\mathrm{D}$ deficiency and metabolic syndrome risk factors has been established [110].

Increased insulin resistance is found associated with low vitamin $\mathrm{D}$ status in a variety of observational studies, for instance, population-based studies in geographically diverse countries [111,112]. Hypponen and Power [109] reported a statistically significant negative association between vitamin D status and hemoglobin Arc. Further, von Hurst et al. [113] proved that improving vitamin D status in insulin resistant patients resulted in ameliorated insulin resistance and sensitivity without change in insulin secretion.

Despite the previous observations, some authors have suggested that the association between Vitamin D and insulin resistance is presumably coincidental [112]. In addition, a recent meta-analysis by Wallace et al. [114] suggests that it is unlikely that vitamin D supplementation has any effect on $\mathrm{T} 2 \mathrm{DM}$ incidence or insulin resistance, and could be a surrogate marker whose attenuation may not be clinically relevant.

\section{VITAMIN D AND MOLECULAR BIOLOGY}

VDRs, found on both the cell and nuclear membranes $[3,4]$, have an influence through genomic and non-genomic pathways in the function and structure of cardiomyocytes and cardiovascular system cells [115,116]. It has also been reported that within this broad group of receptors, certain polymorphisms can be used as pre- 
dictors for developing left ventricular hypertrophy in patients with end stage kidney disease [117] or other diseases, such as Gaucher's variant heart disease [118]. In a study of 293 individuals with angina and hypercholesterolemia, Ortlepp et al. [119] established that the genotype of the VDR is crucial for the prevalence of T2DM and EAC.

Certain allelic variants of the vitamin D carrier protein have been associated with small changes in serum levels of this vitamin. Therefore, it is possible that the levels of vitamin $\mathrm{D}$ and their consequent systemic action may vary according to the genetic characteristics of populations. Hence, we can deduce that the impact to the organs and systems, including the cardiovascular system, will depend in part on the genotype of each patient [120].

We consider important to determine the relationship between certain polymorphisms of genes associated with VDRs [121], which could modify their spatial conformation and their expression in their signaling pathways. Alternatively, the genomics and the proteomics of all components of the metabolic pathway of vitamin $\mathrm{D}$ (enzymes and vitamin $\mathrm{D}$ binding protein) should be analyzed to reveal the degree to which vitamin $\mathrm{D}$ level changes affects the cardiovascular system. In fact, genetic variability may explain the ambivalence in literature, since studies were conducted on specific ethnic groups.

\section{CONCLUSIONS}

Vitamin D is actively involved in multiple metabolic pathways, including those involved in the homeostasis of the cardiovascular system. Low vitamin D levels have been identified as a risk factor for several major cardiovascular diseases [122], including hypertension and pulmonary hypertension, atherosclerosis, $\mathrm{CAD}$, vascular insufficiency, stroke, HF, and AF. Despite the presented information, evidence about these associations remains ambivalent, since a large number of results generated by basic studies and animal models are in contrast with the information obtained in randomized controlled studies. In the current state of knowledge, it may be too early to consider vitamin $\mathrm{D}$ as an instrument to either estimate or mitigate residual cardiovascular risk. For this reason, in our opinion, further studies should assess the role of vitamin D in relation with different pathologies; in the context of the variability of the genes that code for VDRs, enzymes and metabolites, since they directly interact with metabolic pathways related to this vitamin. Nevertheless some of these pathways may still need to be elucidated.

We consider that it is necessary to continue exploring the cardiovascular effect of vitamin $\mathrm{D}$, and to analyze the associations and risks related to changes in the levels of this molecule in different populations. This information may provide improved clinical guidelines, which would indicate the need to monitor the levels of this vitamin in the general population, in some ethnicities or specific groups, regarding these pathologies. However, it is unclear whether vitamin D supplementation can reduce cardiovascular risk or mitigate cardiovascular disease. Therefore, we consider that this molecule should not be recommended for this indication to the general population.

\section{Conflict of interest}

No potential conflict of interest relevant to this article was reported.

\section{Acknowledgments}

We would like to extend our acknowledgments to the Universidad Anahuac México Norte and the Instituto Nacional de Cardiología Ignacio Chavez.

\section{REFERENCES}

1. Wacker M, Holick MF. Sunlight and vitamin D: a global perspective for health. Dermatoendocrinol 2013;5:51-108.

2. Holick MF, Chen TC. Vitamin D deficiency: a worldwide problem with health consequences. Am J Clin Nutr 2008;87:1080S-1086S.

3. Morris HA. Vitamin D activities for health outcomes. Ann Lab Med 2014;34:181-186.

4. Parker J, Hashmi O, Dutton D, et al. Levels of vitamin D and cardiometabolic disorders: systematic review and meta-analysis. Maturitas 2010;65:225-236.

5. Lappe JM, Travers-Gustafson D, Davies KM, Recker RR, Heaney RP. Vitamin D and calcium supplementation reduces cancer risk: results of a randomized trial. Am J Clin Nutr 2007;85:1586-1591.

6. El-Moaty Zaher HA, El-Komy MH, Hegazy RA, Mohamed 
El Khashab HA, Ahmed HH. Assessment of interleukin-17 and vitamin D serum levels in psoriatic patients. J Am Acad Dermatol 2013;69:840-842.

7. Poon AH, Mahboub B, Hamid Q. Vitamin D deficiency and severe asthma. Pharmacol Ther 2013;140:148-155.

8. Hong Q, Xu J, Xu S, Lian L, Zhang M, Ding C. Associations between serum 25-hydroxyvitamin $\mathrm{D}$ and disease activity, inflammatory cytokines and bone loss in patients with rheumatoid arthritis. Rheumatology (Oxford) 2014;53:1994-2001.

9. Konikowska K, Regulska-Ilow B. The role of diet in multiple sclerosis. Postepy Hig Med Dosw (Online) 2014;68:325333.

10. Pappa HM, Gordon CM, Saslowsky TM, et al. Vitamin D status in children and young adults with inflammatory bowel disease. Pediatrics 2006;118:1950-1961.

11. Belenchia AM, Tosh AK, Hillman LS, Peterson CA. Correcting vitamin $\mathrm{D}$ insufficiency improves insulin sensitivity in obese adolescents: a randomized controlled trial. Am J Clin Nutr 2013;97:774-781.

12. Pludowski P, Karczmarewicz E, Bayer M, et al. Practical guidelines for the supplementation of vitamin $\mathrm{D}$ and the treatment of deficits in Central Europe: recommended vitamin $\mathrm{D}$ intakes in the general population and groups at risk of vitamin D deficiency. Endokrynol Pol 2013;64:319-327.

13. Razzaque MS. The dualistic role of vitamin $\mathrm{D}$ in vascular calcifications. Kidney Int 2011;79:708-714.

14. Christakos S, Ajibade DV, Dhawan P, Fechner AJ, Mady LJ. Vitamin D: metabolism. Endocrinol Metab Clin North Am 2010;39:243-253.

15. Campbell MJ. Vitamin D and the RNA transcriptome: more than mRNA regulation. Front Physiol 2014;5:181.

16. Wong MS, Leisegang MS, Kruse C, et al. Vitamin D promotes vascular regeneration. Circulation 2014;130:976986.

17. Wang TJ, Pencina MJ, Booth SL, et al. Vitamin D deficiency and risk of cardiovascular disease. Circulation 2008;117:503-511.

18. Holick MF. Vitamin D deficiency. N Engl J Med 2007;357:266-281.

19. Looker AC, Johnson CL, Lacher DA, Pfeiffer CM, Schleicher RL, Sempos CT. Vitamin D status: United States, 2001-2006. NCHS Data Brief 2011;(59):1-8.

20. Lavie CJ, Lee JH, Milani RV. Vitamin D and cardiovascular disease will it live up to its hype? J Am Coll Cardiol
2011;58:1547-1556.

21. Ross AC, Manson JE, Abrams SA, et al. The 2011 report on dietary reference intakes for calcium and vitamin $\mathrm{D}$ from the Institute of Medicine: what clinicians need to know. J Clin Endocrinol Metab 2011;96:53-58.

22. Holick MF, Binkley NC, Bischoff-Ferrari HA, et al. Evaluation, treatment, and prevention of vitamin $\mathrm{D}$ deficiency: an Endocrine Society clinical practice guideline. J Clin Endocrinol Metab 2011;96:1911-1930.

23. Wortsman J, Matsuoka LY, Chen TC, Lu Z, Holick MF. Decreased bioavailability of vitamin D in obesity. Am J Clin Nutr 2000;72:690-693.

24. Bidgoli SA, Azarshab H. Role of vitamin D deficiency and lack of sun exposure in the incidence of premenopausal breast cancer: a case control study in Sabzevar, Iran. Asian Pac J Cancer Prev 2014;15:3391-3396.

25. Cipriani C, Pepe J, Piemonte S, Colangelo L, Cilli M, Minisola S. Vitamin D and its relationship with obesity and muscle. Int J Endocrinol 2014;2014:841248.

26. Libby P, Theroux P. Pathophysiology of coronary artery disease. Circulation 2005;111:3481-3488.

27. Davignon J, Ganz P. Role of endothelial dysfunction in atherosclerosis. Circulation 2004;109(23 Suppl 1):III27$\mathrm{III}_{32}$.

28. Kunadian V, Ford GA, Bawamia B, Qiu W, Manson JE. Vitamin $\mathrm{D}$ deficiency and coronary artery disease: a review of the evidence. Am Heart J 2014;167:283-291.

29. Andrukhova O, Slavic S, Zeitz U, et al. Vitamin D is a regulator of endothelial nitric oxide synthase and arterial stiffness in mice. Mol Endocrinol 2014;28:53-64.

30. Raymond MA, Desormeaux A, Labelle A, et al. Endothelial stress induces the release of vitamin $\mathrm{D}$-binding protein, a novel growth factor. Biochem Biophys Res Commun 2005;338:1374-1382.

31. Zittermann A, Schleithoff SS, Koerfer R. Putting cardiovascular disease and vitamin $\mathrm{D}$ insufficiency into perspective. Br J Nutr 2005;94:483-492.

32. Khalili H, Talasaz AH, Salarifar M. Serum vitamin D concentration status and its correlation with early biomarkers of remodeling following acute myocardial infarction. Clin Res Cardiol 2012;101:321-327.

33. Carlson N, Mah R, Aburto M, Peters MJ, Dupper MV, Chen LH. Hypovitaminosis D correction and high-sensitivity C-reactive protein levels in hypertensive adults. Perm J 2013;17:19-21.

34. Stach K, Kalsch AI, Nguyen XD, et al. 1 $\alpha, 25$-Dihydroxyvita- 
min $D_{3}$ attenuates platelet activation and the expression of VCAM-1 and MT1-MMP in human endothelial cells. Cardiology 2011;118:107-115.

35. Karur S, Veerappa V, Nanjappa MC. Study of vitamin D deficiency prevalence in acute myocardial infarction. Int J Cardiol Heart Vessels 2014;3:57-59.

36. Lee JH, Gadi R, Spertus JA, Tang F, O’Keefe JH. Prevalence of vitamin $\mathrm{D}$ deficiency in patients with acute myocardial infarction. Am J Cardiol 2011;107:1636-1638.

37. Siasos G, Tousoulis D, Oikonomou E, et al. Vitamin D serum levels are associated with cardiovascular outcome in coronary artery disease. Int J Cardiol 2013;168:4445-4447.

38. Jablonski KL, Chonchol M, Pierce GL, Walker AE, Seals DR. 25-Hydroxyvitamin D deficiency is associated with inflammation-linked vascular endothelial dysfunction in middle-aged and older adults. Hypertension 2011;57:6369.

39. Vacek JL, Vanga SR, Good M, Lai SM, Lakkireddy D, Howard PA. Vitamin D deficiency and supplementation and relation to cardiovascular health. Am J Cardiol 2012;109:359-363.

40. Webb DR, Khunti K, Lacy P, et al. Conduit vessel stiffness in British south Asians of Indian descent relates to 25-hydroxyvitamin D status. J Hypertens 2012;30:1588-1596.

41. Brewer LC, Michos ED, Reis JP. Vitamin D in atherosclerosis, vascular disease, and endothelial function. Curr Drug Targets 2011;12:54-6o.

42. Seker T, Gur M, Kuloglu O, et al. Serum 25-hydroxyvitamin $\mathrm{D}$ is associated with both arterial and ventricular stiffness in healthy subjects. J Cardiol 2013;62:361-365.

43. Al Mheid I, Patel R, Murrow J, et al. Vitamin D status is associated with arterial stiffness and vascular dysfunction in healthy humans. J Am Coll Cardiol 2011;58:186-192.

44. Syal SK, Kapoor A, Bhatia E, et al. Vitamin D deficiency, coronary artery disease, and endothelial dysfunction: observations from a coronary angiographic study in Indian patients. J Invasive Cardiol 2012;24:385-389.

45. Chen WR, Qian YA, Chen YD, et al. The effects of low vitamin $\mathrm{D}$ on coronary artery disease. Heart Lung Circ 2014;23:314-319.

46. Joergensen C, Reinhard H, Schmedes A, et al. Vitamin D levels and asymptomatic coronary artery disease in type 2 diabetic patients with elevated urinary albumin excretion rate. Diabetes Care 2012;35:168-172.

47. Lai H, Gerstenblith G, Fishman EK, et al. Vitamin D deficiency is associated with silent coronary artery disease in cardiovascularly asymptomatic African Americans with HIV infection. Clin Infect Dis 2012;54:1747-1755.

48. Hsu JJ, Tintut Y, Demer LL. Vitamin D and osteogenic differentiation in the artery wall. Clin J Am Soc Nephrol 2008;3:1542-1547.

49. Liberman M, Pesaro AE, Carmo LS, Serrano Jr CV. Vascular calcification: pathophysiology and clinical implications. Einstein (Sao Paulo) 2013;11:376-382.

50. Shroff R, Egerton M, Bridel M, et al. A bimodal association of vitamin $\mathrm{D}$ levels and vascular disease in children on dialysis. J Am Soc Nephrol 2008;19:1239-1246.

51. Krasniak A, Drozdz M, Pasowicz M, et al. Factors involved in vascular calcification and atherosclerosis in maintenance haemodialysis patients. Nephrol Dial Transplant 2007;22:515-521.

52. Schmidt N, Brandsch C, Schutkowski A, Hirche F, Stangl GI. Dietary vitamin D inadequacy accelerates calcification and osteoblast-like cell formation in the vascular system of LDL receptor knockout and wild-type mice. J Nutr 2014;144:638-646.

53. Zebger-Gong H, Muller D, Diercke M, et al. 1,25-Dihydroxyvitamin $\mathrm{D}_{3}$-induced aortic calcifications in experimental uremia: up-regulation of osteoblast markers, calcium-transporting proteins and osterix. J Hypertens 2011;29:339-348.

54. Ding Y, Liao W, Yi Z, Xiang W, He X. Cardioprotective role of vitamin D receptor in circulating endothelial cells of ApoE-deficient mice. Int J Clin Exp Med 2015;8:5065-5074.

55. Malik R, Aneni EC, Roberson L, et al. Measuring coronary artery calcification: is serum vitamin D relevant? Atherosclerosis 2014;237:734-738.

56. Ho JS, Cannaday JJ, Barlow CE, Reinhardt DB, Wade WA, Ellis JR. Low 25-OH vitamin D levels are not associated with coronary artery calcium or obstructive stenoses. Coron Artery Dis 2015;26:521-525.

57. Shen H, Bielak LF, Ferguson JF, et al. Association of the vitamin D metabolism gene CYP24A1 with coronary artery calcification. Arterioscler Thromb Vasc Biol 2010;30:2648-2654.

58. Chua GT, Chan YC, Cheng SW. Vitamin D status and peripheral arterial disease: evidence so far. Vasc Health Risk Manag 2011;7:671-675.

59. Melamed ML, Muntner P, Michos ED, et al. Serum 25-hydroxyvitamin D levels and the prevalence of peripheral arterial disease: results from NHANES 2001 to 2004. Arterioscler Thromb Vasc Biol 2008;28:1179-1185. 
6o. Chaudhuri JR, Mridula KR, Alladi S, et al. Serum 25-hydroxyvitamin d deficiency in ischemic stroke and subtypes in Indian patients. J Stroke 2014;16:44-50.

61. Wang Y, Ji H, Tong Y, Zhang ZB. Prognostic value of serum 25-hydroxyvitamin $\mathrm{D}$ in patients with stroke. Neurochem Res 2014;39:1332-1337.

62. Basu S, Millett C. Social epidemiology of hypertension in middle-income countries: determinants of prevalence, diagnosis, treatment, and control in the WHO SAGE study. Hypertension 2013;62:18-26.

63. Guzman NJ. Epidemiology and management of hypertension in the Hispanic population: a review of the available literature. Am J Cardiovasc Drugs 2012;12:165-178.

64. Vongpatanasin W. Resistant hypertension: a review of diagnosis and management. JAMA 2014;311:2216-2224.

65. Moon JY. Recent update of renin-angiotensin-aldosterone system in the pathogenesis of hypertension. Electrolyte Blood Press 2013;11:41-45.

66. Burgaz A, Orsini N, Larsson SC, Wolk A. Blood 25-hydroxyvitamin D concentration and hypertension: a meta-analysis. J Hypertens 2011;29:636-645.

67. Ajabshir S, Asif A, Nayer A. The effects of vitamin D on the renin-angiotensin system. J Nephropathol 2014;3:4143.

68. Tamez H, Kalim S, Thadhani RI. Does vitamin D modulate blood pressure? Curr Opin Nephrol Hypertens 2013;22:204-209.

69. Li YC, Kong J, Wei M, Chen ZF, Liu SQ, Cao LP. 1,25-Dihydroxyvitamin $\mathrm{D}(3)$ is a negative endocrine regulator of the renin-angiotensin system. J Clin Invest 2002;110:229-238.

70. Zhou C, Lu F, Cao K, Xu D, Goltzman D, Miao D. Calcium-independent and 1,25 $(\mathrm{OH})_{2} \mathrm{D}_{3}$-dependent regulation of the renin-angiotensin system in ralpha-hydroxylase knockout mice. Kidney Int 2008;74:170-179.

71. Weng S, Sprague JE, Oh J, et al. Vitamin D deficiency induces high blood pressure and accelerates atherosclerosis in mice. PLoS One 2013;8:e54625.

72. Tare M, Emmett SJ, Coleman HA, et al. Vitamin D insufficiency is associated with impaired vascular endothelial and smooth muscle function and hypertension in young rats. J Physiol 2011;589(Pt 19):4777-4786.

73. Wong MS, Delansorne R, Man RY, Svenningsen P, Vanhoutte PM. Chronic treatment with vitamin D lowers arterial blood pressure and reduces endothelium-dependent contractions in the aorta of the spontaneously hypertensive rat. Am J Physiol Heart Circ Physiol
2010;299:H1226-H1234.

74. Min B. Effects of vitamin D on blood pressure and endothelial function. Korean J Physiol Pharmacol 2013;17:385392.

75. Rostand SG. Vitamin D, blood pressure, and African Americans: toward a unifying hypothesis. Clin J Am Soc Nephrol 2010;5:1697-1703.

76. Scragg R, Sowers M, Bell C. Serum 25-hydroxyvitamin D, ethnicity, and blood pressure in the Third National Health and Nutrition Examination Survey. Am J Hypertens 2007;20:713-719.

77. Hintzpeter B, Mensink GB, Thierfelder W, Muller MJ, Scheidt-Nave C. Vitamin D status and health correlates among German adults. Eur J Clin Nutr 2008;62:10791089.

78. Fares A. Winter hypertension: potential mechanisms. Int J Health Sci (Qassim) 2013;7:210-219.

79. Rostand SG. Ultraviolet light may contribute to geographic and racial blood pressure differences. Hypertension 1997;30(2 Pt 1):150-156.

80. Forman JP, Williams JS, Fisher ND. Plasma 25-hydroxyvitamin $\mathrm{D}$ and regulation of the renin-angiotensin system in humans. Hypertension 2010;55:1283-1288.

81. Nasri H, Behradmanesh S, Ahmadi A, Rafieian-Kopaei M. Impact of oral vitamin D (cholecalciferol) replacement therapy on blood pressure in type 2 diabetes patients: a randomized, double-blind, placebo controlled clinical trial. J Nephropathol 2014;3:29-33.

82. Larsen T, Mose FH, Bech JN, Hansen AB, Pedersen EB. Effect of cholecalciferol supplementation during winter months in patients with hypertension: a randomized, placebo-controlled trial. Am J Hypertens 2012;25:12151222.

83. Forman JP, Scott JB, Ng K, et al. Effect of vitamin D supplementation on blood pressure in blacks. Hypertension 2013;61:779-785.

84. Judd SE, Raiser SN, Kumari M, Tangpricha V. 1,25-Dihydroxyvitamin $\mathrm{D}_{3}$ reduces systolic blood pressure in hypertensive adults: a pilot feasibility study. J Steroid Biochem Mol Biol 2010;121(1-2):445-447.

85. Witham MD, Price RJ, Struthers AD, et al. Cholecalciferol treatment to reduce blood pressure in older patients with isolated systolic hypertension: the VitDISH randomized controlled trial. JAMA Intern Med 2013;173:1672-1679.

86. Witham MD, Nadir MA, Struthers AD. Effect of vitamin D on blood pressure: a systematic review and meta-analysis. 
J Hypertens 2009;27:1948-1954.

87. Elamin MB, Abu Elnour NO, Elamin KB, et al. Vitamin $\mathrm{D}$ and cardiovascular outcomes: a systematic review and meta-analysis. J Clin Endocrinol Metab 2011;96:1931-1942.

88. Beveridge LA, Struthers AD, Khan F, et al. Effect of vitamin D supplementation on blood pressure: a systematic review and meta-analysis incorporating individual patient data. JAMA Intern Med 2015;175:745-754.

89. Demir M, Uyan U, Keceoclu S, Demir C. The relationship between vitamin D deficiency and pulmonary hypertension. Prague Med Rep 2013;114:154-161.

90. Pourdjabbar A, Dwivedi G, Haddad H. The role of vitamin D in chronic heart failure. Curr Opin Cardiol 2013;28:216-222.

91. Meredith AJ, McManus BM. Vitamin D in heart failure. J Card Fail 2013;19:692-711.

92. Choi JH, Ke Q, Bae S, et al. Doxercalciferol, a pro-hormone of vitamin $\mathrm{D}$, prevents the development of cardiac hypertrophy in rats. J Card Fail 2011;17:1051-1058.

93. Gupta GK, Agrawal T, DelCore MG, Mohiuddin SM, Agrawal DK. Vitamin D deficiency induces cardiac hypertrophy and inflammation in epicardial adipose tissue in hypercholesterolemic swine. Exp Mol Pathol 2012;93:8290.

94. Shedeed SA. Vitamin D supplementation in infants with chronic congestive heart failure. Pediatr Cardiol 2012;33:713-719.

95. Schroten NF, Ruifrok WP, Kleijn L, et al. Short-term vitamin D3 supplementation lowers plasma renin activity in patients with stable chronic heart failure: an open-label, blinded end point, randomized prospective trial (VitDCHF trial). Am Heart J 2013;166:357-364.e2.

96. Ford JA, MacLennan GS, Avenell A, et al. Cardiovascular disease and vitamin $\mathrm{D}$ supplementation: trial analysis, systematic review, and meta-analysis. Am J Clin Nutr 2014;100:746-755.

97. Boxer RS, Kenny AM, Cheruvu VK, Vest M, Fiutem JJ, Pina II. Serum 25-hydroxyvitamin D concentration is associated with functional capacity in older adults with heart failure. Am Heart J 2010;160:893-899.

98. Wannamethee SG, Welsh P, Papacosta O, Lennon L, Whincup PH, Sattar N. Elevated parathyroid hormone, but not vitamin $\mathrm{D}$ deficiency, is associated with increased risk of heart failure in older men with and without cardiovascular disease. Circ Heart Fail 2014;7:732-739.

99. Petrone AB, Weir NL, Steffen BT, Tsai MY, Gaziano
JM, Djousse L. Plasma vitamin D-binding protein and risk of heart failure in male physicians. Am J Cardiol 2013;112:827-830.

100.Zoni-Berisso M, Lercari F, Carazza T, Domenicucci S. Epidemiology of atrial fibrillation: European perspective. Clin Epidemiol 2014;6:213-220.

101. Balouch MA, Kolek MJ, Darbar D. Improved understanding of the pathophysiology of atrial fibrillation through the lens of discrete pathological pathways. Glob Cardiol Sci Pract 2014;2014:24-36.

102. Kessel L. Sick sinus syndrome cured by ... vitamin D? Geriatrics 1990;45:83-85.

103. Cardus A, Parisi E, Gallego C, Aldea M, Fernandez E, Valdivielso JM. 1,25-Dihydroxyvitamin $\mathrm{D}_{3}$ stimulates vascular smooth muscle cell proliferation through a VEGF-mediated pathway. Kidney Int 2006;69:1377-1384.

104. Demir M, Uyan U, Melek M. The effects of vitamin D deficiency on atrial fibrillation. Clin Appl Thromb Hemost 2014;20:98-103.

105. Chen WR, Liu ZY, Shi Y, et al. Relation of low vitamin D to nonvalvular persistent atrial fibrillation in Chinese patients. Ann Noninvasive Electrocardiol 2014;19:166-173.

106. Menezes AR, Lavie CJ, DiNicolantonio JJ, et al. Atrial fibrillation in the 21st century: a current understanding of risk factors and primary prevention strategies. Mayo Clin Proc 2013;88:394-409.

107. Qayyum F, Landex NL, Agner BR, Rasmussen M, Jons C, Dixen U. Vitamin D deficiency is unrelated to type of atrial fibrillation and its complications. Dan Med J 2012;59:A4505.

108. Rienstra M, Cheng S, Larson MG, et al. Vitamin D status is not related to development of atrial fibrillation in the community. Am Heart J 2011;162:538-541.

109. Hypponen E, Power C. Vitamin D status and glucose homeostasis in the 1958 British birth cohort: the role of obesity. Diabetes Care 2006;29:2244-2246.

110. Prasad P, Kochhar A. Interplay of vitamin D and metabolic syndrome: a review. Diabetes Metab Syndr 2016;10:105112.

111. Pham NM, Akter S, Kurotani K, et al. Serum 25-hydroxyvitamin $\mathrm{D}$ and markers of insulin resistance in a Japanese working population. Eur J Clin Nutr 2012;66:1323-1328.

112. Heaney RP, French CB, Nguyen S, et al. A novel approach localizes the association of vitamin $\mathrm{D}$ status with insulin resistance to one region of the 25 -hydroxyvitamin $\mathrm{D}$ continuum. Adv Nutr 2013;4:303-310. 
113. von Hurst PR, Stonehouse W, Coad J. Vitamin D supplementation reduces insulin resistance in South Asian women living in New Zealand who are insulin resistant and vitamin D deficient: a randomised, placebo-controlled trial. Br J Nutr 2010;103:549-555.

114. Wallace IR, Wallace HJ, McKinley MC, Bell PM, Hunter SJ. Vitamin D and insulin resistance. Clin Endocrinol (Oxf) 2015 Mar 2 [Epub]. http://dx.doi.org/10.1111/ cen.12760.

115. Polly P, Tan TC. The role of vitamin D in skeletal and cardiac muscle function. Front Physiol 2014;5:145.

116. Zhao G, Simpson RU. Membrane localization, caveolin-3 association and rapid actions of vitamin $\mathrm{D}$ receptor in cardiac myocytes. Steroids 2010;75(8-9):555-559.

117. Testa A, Mallamaci F, Benedetto FA, et al. Vitamin D receptor (VDR) gene polymorphism is associated with left ventricular (LV) mass and predicts left ventricular hypertrophy (LVH) progression in end-stage renal disease (ESRD) patients. J Bone Miner Res 2010;25:313-319.

118. Greenwood A, Altarescu G, Zimran A, Elstein D. Vitamin
D receptor (VDR) polymorphisms in the cardiac variant of Gaucher disease. Pediatr Cardiol 2010;31:30-32.

119. Ortlepp JR, Lauscher J, Hoffmann R, Hanrath P, Joost HG. The vitamin $\mathrm{D}$ receptor gene variant is associated with the prevalence of type 2 diabetes mellitus and coronary artery disease. Diabet Med 2001;18:842-845.

120. Perna L, Felix JF, Breitling LP, et al. Genetic variations in the vitamin $\mathrm{D}$ binding protein and season-specific levels of vitamin D among older adults. Epidemiology 2013;24:104-109.

121. Liu Z, Liu L, Chen X, He W, Yu X. Associations study of vitamin $\mathrm{D}$ receptor gene polymorphisms with diabetic microvascular complications: a meta-analysis. Gene 2014;546:6-10.

122. Pekkanen MP, Ukkola O, Hedberg P, et al. Serum 25-hydroxyvitamin $\mathrm{D}$ is associated with major cardiovascular risk factors and cardiac structure and function in patients with coronary artery disease. Nutr Metab Cardiovasc Dis 2015;25:471-478. 